\title{
DAYA TARIK PEMBERI-KERJA MENURUT PERSEPSI GENERASI X DAN Y
}

\author{
Tifani Onibala \\ Universitas Bunda Mulia \\ tonibala@bundamulia.ac.id \\ Tria Rendi Manurun ${ }^{2}$ \\ Universitas Bunda Mulia \\ triarendymanurun@yahoo.com
}

\begin{abstract}
This study attempts to identify the dimensions of employers' attractivenes, to examine their perceived important levels.In order to respond to these questions, a field study is conducted and data is collected from a purposive of 169 respondents (employed and un-employed college students). Analysis results indicated that there are differences perceptions between $X$ and $Y$ generations. Generation $X$ put higher expectations on the condition of the company, corporate image, training and development, job security, employment conditions, teamcohesion, leadership style, diversity, work schedule autonomy and decisionmaking autonomy, task variety \& significance, flexible working environment. Y generation put higher expectation on the location of work, commitment/atmosphere, CSR, and the work environment.

Keywords: employer attractiveness, generation $X$, generation $Y$
\end{abstract}

\begin{abstract}
ABSTRAK
Penelitian ini bertujuan untuk mengetahui pandangan tenaga kerja berbeda generasi, khususnya generasi $\mathrm{X}$ dan $\mathrm{Y}$ mengenai daya tarik pemberi-kerja mana yang menjadi harapan mereka. Penelitian ini menggunakan statistik deskriptif. Responden penelitian adalah angkatan kerja baik karyawan maupun potensial kandidat (mahasiswa) yang tahun kelahirannya tergolong generasi $\mathrm{X}$ dan Y. Teknik pengambilan sampel adalah non-probalitas dengan metode purposive sampling. Sampel berjumlah 169 responden. Hasil analisis deksriptif menunjukkan bahwa pandangan generasi X dan Y terhadap dimensidimensi daya tarik perusahaan berbeda. Generasi X menaruh harapan yang lebih tinggi terhadap dimensi kondisi perusahaan, citra perusahaan, penerapan pelatihan dan pengembangan, kemanan kerja, kondisi ketenagakerjaan, kerjasama tim, kepemimpinan, keberagaman, otonomi jadwal kerja dan pengambilan keputusan, tugas yang bervariasi dan fleksibilitas lingkungan kerja, sedangkan generasi Y lebih mengharapkan lokasi kerja, komitmen dan atmosfir, CSR, dan lingkungan kerja daripada generasi X.
\end{abstract}

Kata Kunci: daya tarik pemberi-kerja, generasi X, generasi $\mathrm{Y}$

\section{PENDAHULUAN}

Tenaga kerja usia produktif saat ini tercakup tiga tipe generasi, yaitu Zoomers/baby boomers (kelahiran tahun 1946-1964), X (1965-1980), dan Y (19811997) yang memiliki nilai, perspektif, dan pola pikir serta prioritas hidup yang berbeda-beda (Cran, 2014). Perbedaan ini disebabkan oleh kejadian-kejadian yang dialaminya termasuk ekonomi, sosial dan pengalaman (Angeline, 2011). Dengan perbedaan dari ketiga generasi ini membuat mereka cenderung memilih organisasi yang dapat menawarkan manfaat yang dapat memenuhi kebutuhan, perilaku, cara kerja, dan dapat mengaplikasikan keterampilan yang mereka miliki di tempat kerja. Sebagian perbedaan dari ketiga generasi ini disajikan pada Tabel 1. 
Tabel 1: Perbedaan Keterampilan Generasi Baby Boomer, X, dan Y

\begin{tabular}{lll}
\hline \multicolumn{1}{c}{ Gen Y } & \multicolumn{1}{c}{ Gen X } & \multicolumn{1}{c}{$\begin{array}{c}\text { Baby } \\
\text { Boomer/Zoomer }\end{array}$} \\
\hline Pintar teknologi & $\begin{array}{l}\text { Fokus pada } \\
\text { proyek }\end{array}$ & $\begin{array}{l}\text { Trampil } \\
\text { berinteraksi dengan } \\
\text { orang (people } \\
\text { skills) }\end{array}$ \\
$\begin{array}{l}\text { Belajar dalam } \\
\text { kelompok }\end{array}$ & Independen & $\begin{array}{l}\text { Berinisiatif (self } \\
\text { starter) }\end{array}$ \\
\hline $\begin{array}{l}\text { Kreatif } \\
\text { Ramah dan }\end{array}$ & Strategis & $\begin{array}{l}\text { Fokus pada tujuan } \\
\text { (goal setter) }\end{array}$ \\
Reruka & berhati-hati & $\begin{array}{l}\text { Profesional dan } \\
\text { kurang membuka } \\
\text { diri }\end{array}$ \\
$\begin{array}{l}\text { Mudah dan } \\
\text { menyesuaikan } \\
\text { diri (adaptif) }\end{array}$ & $\begin{array}{l}\text { Adaptif secara } \\
\text { strategi }\end{array}$ & $\begin{array}{l}\text { Adaptif hanya bila } \\
\text { diharuskan }\end{array}$ \\
\hline
\end{tabular}

Sumber: Cran, 2014

Organisasi harus benar-benar memahami karakteristik dari karyawan-karyawan potensial yang berbeda generasi ini agar dapat menarik mereka untuk bekerja di perusahaan (pemberi-kerja).

Untuk menarik mereka, pemberi-kerja harus memiliki daya tarik tersendiri. Daya tarik pemberi-kerja didefinisikan sebagai manfaat yang dibayangkan oleh karyawan potensial jika bekerja di organisasi tertentu (Berthon, 2005). Semakin menarik pemberi-kerja dianggap oleh karyawan potensial, semakin kuat ekuitas merek organisasi pemberi-kerja tersebut (Berthon, 2005). Dengan kata lain, minat karyawan potensial untuk bergabung di organisasi tersebut akan semakin tinggi. Organisasi yang memiliki daya tarik akan lebih mudah dalam mencari karyawan yang sesuai dengan targetnya. Oleh karena itu, organisasi perlu menyesuaikan daya tariknya dengan nilai-nilai, perilaku, gaya hidup dan kebutuhan dari target karyawannya di berbeda generasi.

Saat ini, lapangan pekerjaan di Indonesia didominasi oleh generasi $\mathrm{X}$ dan $\mathrm{Y}$. Dari data karir.com tahun 2015 (dalam swa.co.id, 2015) menunjukkan bahwa Gen
X yang memiliki gelar S1 sebanyak $64 \%$ dan tersebar dalam proporsi jabatan sebagai Department Manager (23\%), Senior Staff (18\%) dan Supervisor (17\%). Sedangkan, generasi $\mathrm{Y}, 62 \%$ di antaranya mengantongi gelar S1, dan meski $51 \%$ di antara total jumlah pengguna fitur karir.com masih berada pada entry level, dimana untuk posisi Senior Staff mencapai 22\% dan pada tingkat Supervisor 13\%. Dari data tersebut dapat dilihat bahwa pertumbuhan karir generasi $\mathrm{Y}$ lebih progresif dibandingkan dengan generasi $\mathrm{X}$ terbukti dari terdapatnya irisan di beberapa tingkat jabatan.

Data BPS 2015 juga menyebutkan bahwa jumlah karyawan generasi Y (Millenial) di Indonesia telah mencapai 84 juta orang atau $50 \%$ dari penduduk usia produktif. Pada tahun 2020, generasi Y akan mendominasi dunia kerja dengan populasi usia produktif $70 \%$ dari total penduduk. (kompas.com, 2017)

Berdasarkan uraian di atas, penelitian ini akan fokus pada persepsi daya tarik pemberi-kerja dua generasi angkatan kerja saja, yaitu $\mathrm{X}$ dan $\mathrm{Y}$.

Dari hasil penelitian ini diharapkan dapat memberikan gambaran bagi pemberi-kerja 
agar dapat menciptakan daya tarik yang sesuai dengan apa yang menjadi daya tarik bagi sasaran karyawannya. Pemberi-kerja harus memiliki daya tarik tertentu untuk dapat menarik calon karyawan yang diinginkannya, karena karyawan yang memiliki kemampuan juga akan cenderung memilih perusahaan yang dapat memberikan apa yang diharapkannya.

\section{TINJAUAN PUSTAKA}

\section{Generasi}

Generasi merupakan kelompok dengan tahun kelahiran, usia, lokasi dan peristiwa kehidupan yang hampir sama. Individu pada generasi yang sama mengalami sejarah, perekonomian, dan pengalaman-pengalaman sosial yang sama, mereka juga cenderung memiliki nilai kerja, sikap, dan perilaku yang sama juga. (Smola and Sutton, 2002; Zemke et al., 2000; Angeline 2011).

Tenaga kerja umur produktif saat ini tercakup tiga tipe generasi, yaitu baby boomers, X, dan Y (Cran, 2014). Sub-bab berikut akan menjelaskan tentang tiga tipe generasi ini. Tabel berikut

\section{Generasi Baby Boomer (Zoomer)}

Menurut Moses Znaimer (Cran, 2014) baby boomer diistilahkan sebagai zoomer. Istilah ini muncul karena pandangannya yang terbalik tentang baby boomer yang modern dan menua. Menurutnya, zoomer adalah seorang baby boomer yang menolak menjadi tua.

Masih menurut Cran, para zoomer menyukai teknologi hanya bila mudah dipelajari dan membuat pekerjaan mereka menjadi lebih mudah dan biasanya mereka akan menolak teknologi apabila tidak membuat pekerjaan mereka lebih mudah atau melibatkan kurva belajar panjang.

\section{Generasi X (tahun kelahiran 1965 - 1980)}

Generasi ini digambarkan sebagai generasi yang berpikiran wirausaha, mandiri, sudah nyaman akan perubahan, namun cenderung tidak setia pada organisasi pemberi kerja (Yu and Miller, 2005; Onibala, 2016).

\section{Generasi Y (tahun kelahiran > 1980)}

Generasi Y adalah masyarakat yang lahir setelah tahun 1980. Generasi ini juga biasa disebut dengan istilah generasi internet (atau dot.com), echo boomers, millenials dan nexters (Broadbridge et al., 2007). Generasi ini yang masa kecilnya penuh dengan segala macam kegiatan, sehingga mereka menjadi sangat bosan di tempat kerja yang tidak menantang, tidak multitasking, atau tidak menghargai kontribusi mereka. Pandangan generasi Y dibentuk oleh segala tren atau kejadian semasa hidup mereka, yaitu sebagai berikut:

- Teknologi semenjak mereka lahir

- Acara realitas di TV

- Perceraian para Baby Boomers

- Ruang kelas yang multikultural

- Kreativitas yang diajarkan di sekolah

- Orangtua mengajarkan mereka untuk berani berbicara

- Mereka sudah dihargai kalau hadir

- Jejaring sosial (MSN, Facebook, Myspace, dll)

Dalam kehidupannya, generasi $\mathrm{Y}$ melihat tingkat kekerasan meningkat dan terorisme global, maka sikap mereka adalah hidup itu berharga. Generasi Y secara umum sangat demonstratif dan mencintai teman-teman mereka. (Cran, 2014).

Dalam pekerjaan, generasi $\mathrm{Y}$ ratarata akan berganti pekerjaan sampai dua puluh kali semasa hidup mereka, dibandingkan dengan para tradisionalis yang bekerja pada pemberi kerja yang sama sampai mereka pensiun. Generasi Y tidak setia kepada perusahaan, sebaliknya mereka setia kepada teman-teman mereka. Apabila mereka merasa bos atau rekan kerja mereka seperti teman mereka, maka mereka akan tetap tinggal di perusahaan. Apabila mereka tidak menyukai atasan mereka maka 
mereka akan berhenti tanpa berpikir. (Cran, 2014)

Menurut Raines (2002; Onibala dan Novita, 2016), generasi Y (millennials) memiliki karakteristik sebagai berikut:

1) Percaya diri (confident). Dibesarkan oleh orang tua yang percaya akan pentingnya kepercayaan diri, secara karakter mereka menganggap diri mereka siap untuk mengatasi tantangan. Para manajer yang memegang pemahaman "membayar hak Anda" dan rekan kerja yang tidak berpikir bahwa suatu pendapat tidak layak didengarkan kecuali dari seseorang yang berpengalaman bertahun-tahun akan menganggap sikap bisa melakukan apapun (can-do attitude) dari generasi ini meresahkan dan menganggu mereka.

2) Penuh harapan (hopeful). Mereka dideskripsikan sebagai generasi yang optimis namun praktis. Mereka percaya akan masa depan dan peran mereka didalamnya. Mereka mengharapkan lingkungan kerja yang menantang, kolaboratif, kreatif, menyenangkan, dan menguntungkan secara finansial.

3) Berorientasi pada tujuan dan prestasi (goal- and achievementoriented). Banyak milenial yang tiba di perusahaan pada hari pertama kerja dengan tujuan pribadinya.

4) Memikirkan kepentingan banyak orang (civic-minded). Mereka diajarkan untuk memikiran kepentingan bersama. Mereka memiliki tingkat sukarelawan yang tinggi, dan berharap perusahaan tempat mereka bekerja untuk berkontribusi dalam masyarakat/lingkungan dan beroperasi dengan cara yang dapat menciptakan lingkungan berkelanjutan.

5) Inklusif (inclusive). Generasi ini terbiasa terorganisir di dalam tim dan memastikan tidak ada satu pun dalam kelompok yang tertinggal. Mereka berharap mendapatkan nafkah di lingkungan kerja yang adil untuk semua, dimana perbedaan (diversity) sudah merupakan norma - mereka akan menggunakan kekuatan kolektif mereka jika mereka merasa ada orang yang diperlakukan secara tidak adil.

\section{Daya Tarik Pemberi-Kerja}

Daya tarik merupakan keunggulan bersaing sebagai pemberi-kerja untuk menarik karyawan potensial yang memiliki keahlian dan pengetahuan yang cocok dengan peryaratan dari organisasi (Cable \& Turbanm, 2001; Jiang dan Iles, 2011). Menarik pelamar kerja yang berkualitas dengan jumlah yang tepat merupakan hal krusial untuk kesuksesan organisasi. (Jiang dan Iles, 2011).

Menurut Turban (1998; Jiang dan Iles, 2011), daya tarik organisasi merupakan berhubungan dengan citra organisasi, karakteristik pekerjaan, dan karakteristik organisasi.

\section{METODE PENELITIAN}

Penelitian ini menggunakan statistik deskriptif. Penelitian ini menggunakan statistik deskriptif karena dianggap cocok dengan latar belakang permasalahan dan juga untuk lebih menjelaskan mengenai fenomena sosial. Menurut Ferdinand (2014), 'penelitian manajemen dapat dipandang sebagai sebuah penelitian mengenai proses sosial yang terjadi dalam manajemen yang mampu menguak berbagai "black box" yang terdapat dalam proses manajemen itu sendiri'. Dengan kata lain, penelitian manajemen harusnya tidak hanya berwajah kuantitatif saja tapi harus mampu memberikan 
penjelasan secara sosial bagi seluruh aspek manajerial yang menjadi perhatian peneliti.

\section{Populasi dan Sampel}

Populasi penelitian ini adalah angkatan kerja baik yang sudah bekerja maupun yang belum bekerja yang tahun kelahirannya tergolong generasi $\mathrm{X}$ dan Y.

Teknik pengambilan sampel menggunakan non-probabilitas dengan metode purposive sampling. Responden adalah angkatan kerja yang tahun kelahirannya antara 1965 - 1998. Jumlah sampel adalah 169 responden.

\section{Instrumen Penelitian}

Intrumen penelitian ini diambil dari penelitian Broek (2015), dimana daya tarik perusahaan meliputi lokasi kerja; kondisi perusahaan; komitmen/atmosfir; citra organisasi; corporate social responsibility (CSR); pelatihan dan pengembangan, keamanan kerja; lingkungan kerja; kondisi ketenagakerjaan; kerjasama tim; gaya kepemimpinan; lingkungan kerja yang menjunjung tinggi keanekaragaman; keterbiasaan (familiarity); otonomi mengatur jam kerja; otonomi pengambilan keputusan.

\section{Profil Responden}

HASIL DAN PEMBAHASAN

Tabel 2: Profil Responden $(n=169)$

\begin{tabular}{|c|c|c|}
\hline Profil & $\begin{array}{c}\text { Freku } \\
\text { nsi }\end{array}$ & $\%$ \\
\hline \multicolumn{3}{|c|}{ Jender } \\
\hline Laki-Laki & 79 & 46,7 \\
\hline Perempuan & 90 & 53,3 \\
\hline \multicolumn{3}{|c|}{ Tahun Lahir } \\
\hline $1965-1970$ & 4 & 2,4 \\
\hline $1971-1975$ & 9 & 5,3 \\
\hline $1976-1980$ & 20 & 11,8 \\
\hline $1981-1985$ & 13 & 7,7 \\
\hline $1986-1990$ & 19 & 11,2 \\
\hline $1991-1998$ & 104 & 61,5 \\
\hline \multicolumn{3}{|c|}{ Pekerjaan } \\
\hline Karyawan Swasta & 101 & 59,8 \\
\hline PNS & 1 & 6 \\
\hline Mahasiswa & 60 & 35,5 \\
\hline Lain-Lain & 6 & 3,6 \\
\hline \multicolumn{3}{|c|}{ Rencana Setelah Lulus Kuliah (responden } \\
\hline
\end{tabular}




\begin{tabular}{|c|c|c|}
\hline \multicolumn{3}{|l|}{ Mahasiswa) } \\
\hline $\begin{array}{c}\text { Melamar Pekerjaan di } \\
\text { Perusahaan }\end{array}$ & 43 & 71,6 \\
\hline Membuka Usaha Sendiri & 13 & 21,6 \\
\hline $\begin{array}{c}\text { Meneruskan Usaha atau Bisnis } \\
\text { Keluarga }\end{array}$ & 4 & 6,6 \\
\hline \multicolumn{3}{|c|}{ Tujuan Jangka Panjang (responden Mahasiswa) } \\
\hline Berkarir sebagai Profesional & 26 & 43,3 \\
\hline Wirausahawan & 34 & 56,6 \\
\hline
\end{tabular}

Responen penelitian ini sebagian besar adalah ber-jender perempuan yaitu sebesar 53,3\%. Berdasarkan tahun kelahiran, responden yang tergolong generasi $\mathrm{X}$ adalah sebanyak 33 dan generasi Y sebanyak 136 responden. Responden sebagian besar berstatus sudah bekerja (karyawan swasta dan PNS) yaitu sebanyak 102 responden, dan sebanyak 60 responden masih berstatus mahasiswa.

Terdapat dua pertanyaan tambahan dalam profil yang ditujukan hanya untuk mahasiswa, yaitu rencana setelah lulus kuliah dan tujuan jangka panjang responden mahasiswa. Dari pertanyaan tersebut, sebagian besar mahasiswa akan melamar pekerjaan di perusahaan tertentu yaitu sebanyak 43 orang dari 60 responden mahasiswa. Namun setelah ditanyakan tujuan jangka panjang sebanyak 34 responden memilih menjadi wirausahawan, sedangkan sisanya 26 responden memiliki tujuan jangka panjang berkarir sebagai profesional.

Pembahasan

Ringkasan hasil penelitian dapat dilihat pada Tabel 3.

Tabel 3: Hasil Statistik Deskriptif (Nilai Mean) Persepsi Generasi X dan Y ( $n=169)$

\begin{tabular}{lcc}
\hline Daya Tarik & Gen X & Gen Y \\
\hline Lokasi Kerja & 4.19 & $\mathbf{4 . 2 1}$ \\
\hline Kondisi Perusahaan & 4.24 & 4.22 \\
\hline Komitmen/Atmosfir & 4.35 & 4.37 \\
\hline Citra Organisasi & 4.33 & 4.3 \\
CSR & 4.14 & $\mathbf{4 . 2 9}$ \\
\hline Pelatihan dan Pengembangan & 4.55 & 4.52 \\
Keamanan Kerja & $\mathbf{4 . 8}$ & 4.66 \\
Lingkungan Kerja & 4.7 & 4.71 \\
\hline Kondisi Ketenagakerjaan & $\mathbf{4 . 7 6}$ & 4.67 \\
\hline Kerjasaman Tim & $\mathbf{4 . 6 2}$ & 4.51 \\
Gaya Kepemimpinan & $\mathbf{4 . 5 2}$ & 4.39 \\
\hline Keanekaragaman Lingkungan & 4.45 & 4.4 \\
Kerja & $\mathbf{4 . 2 7}$ & 4.08 \\
\hline Keterbiasaan (Familiarity) & 4 & 3.97 \\
\hline Otonomi Mengatur Jam Kerja & & \\
\hline
\end{tabular}




\begin{tabular}{lcc}
\hline Otonomi Pengambilan Keputusan & $\mathbf{4 . 2 7}$ & 4.03 \\
\hline Tugas yang Bervariasi \& & $\mathbf{4 . 3}$ & 4.06 \\
Berdampak Signifikasn & $\mathbf{3 . 9 2}$ & 3.86 \\
\hline Lingkungan Kerja yang Fleksibel & \\
\hline
\end{tabular}

Penelitian ini menunjukkan bahwa tidak ada perbedaan pandangan yang signifikan antara generasi $\mathrm{X}$ dan $\mathrm{Y}$, namun ada beberapa faktor daya tarik yang menunjukkan perbedaan yaitu faktor tanggung jawab sosial (corporate social responsibity - CSR). Generasi Y lebih mengharapkan perusahaan yang melakukan CSR dibandingkan generasi $X$. Hal ini mendukung pendapat Raines (2002; Onibala dan Novita, 2016) yang menyatakan bahwa generasi $\mathrm{Y}$ memiliki karakteristik lebih memikirkan kepentingan banyak orang (civic minded).

Dalam hal keamanan kerja, generasi $X$ lebih mengharapkan faktor ini dibandingkan generasi $\mathrm{Y}$. Hal ini dapat disebabkan karena generasi $\mathrm{X}$ pada umumnya sudah memasuki usia mapan dan siap dan/atau sudah berkeluarga, sehingga lebih mengharapkan pekerjaan tetap agar dapat membiayai keluarganya, sedangkan generasi $\mathrm{Y}$ yang pada umumnya masih muda masih belum terlalu menganggap faktor ini adalah hal yang paling penting karena masih perlu mencari pengalaman yang lebih.

Perbedaan pandangan juga terjadi pada faktor keterbiasaan (familiarity) atau perusahaan yang sudah sering terdengar oleh responden. Bagi generasi X bekerja di perusahaan yang sudah umum dikenal sangat diharapkan oleh generasi ini, berbeda dengan generasi $\mathrm{Y}$ yang harapannya tidak sebesar generasi X. Hal ini dikarenakan yang menjadi responden mayoritas adalah generasi $\mathrm{Y}$ yang masih mahasiswa sehingga masih belum terlalu berharap bekerja di perusahaan yang ternama.
Pandangan yang berbeda dari kedua generasi ini juga terjadi pada faktor otonomi pengambilan keputusan dan pekerjaan yang bervariasi dan berdampak signifikan bagi orang lain. Generasi X memandang bahwa kedua faktor ini merupakan hal yang sangat diharapkan dalam bekerja, sedangkan bagi generasi Y hal ini diharapkan bagi mereka namun lebih dibawah daripada generasi X. Hal ini dapat disebabkan karena generasi X saat ini sudah berstatus karyawan dengan posisi atau level pekerjaan yang sudah di atas aras staff, sehingga mengharapkan diberikan kesempatan untuk mengambil keputusan atau hal itu sudah menjadi tanggung jawab mereka, sedangkan bagi generasi $\mathrm{Y}$ yang pada umumnya responden masih berstatus mahasiswa dan karyawan yang masih pada aras kerja yang belum terlalu tinggi masih belum terlalu mengharapkan diberikan otonomi dalam pengambilan keputusan. Dalam hal pekerjaan yang bervariasi dan berdampak signifikan bagi orang lain, karena generasi $\mathrm{X}$ sudah dalam kondisi bekerja sehingga mereka tahu bahwa pekerjaan yang bervariasi akan mengurangi kejenuhan dalam bekerja, sedangkan bagi generasi $\mathrm{Y}$ yang pada umumnya mahasiswa masih belum membayangkan pekerjaan yang bagaimana yang akan mereka hadapai nanti di dunia kerja.

\section{SIMPULAN DAN SARAN}

\section{Simpulan}

Hasil penelitian ini menunjukkan bahwa terdapat perbedaan pandangan mengenai faktor-faktor yang menjadi daya tarik perusahaan bagi generasi $\mathrm{X}$ dan generasi Y. Faktor-faktor tersebut adalah tanggung jawab sosial (CSR), keamanan 
kerja (job security), keterbiasaan (familiarity), dan faktor otonomi pengambilan keputusan dan pekerjaan yang bervariasi dan berdampak signifikan bagi orang lain.

\section{Saran}

Bagi pemberi kerja yang menyasar karyawan yang berbeda generasi, sebaiknya menciptakan daya tarik yang diharapkan oleh karyawan yang berbeda generasi.

Program CSR bukan saja hanya menjadi tanggung jawab perusahaan di lingkungan dan masyarakat sekitar saja, namun juga bisa menjadi suatu strategi rekrutmen pemberi-kerja untuk mendapatkan karyawan generasi Y.

Bagi pemberi-kerja yang ingin merekrut karyawan generasi $\mathrm{X}$ untuk posisi tertentu, perusahaan perlu memperhatikan beberapa faktor, antara lain keamanan kerja, kondisi ketenagakerjaan, kerjasama tim, gaya kepemimpinan, keterbiasaan (familiarity) perusahaan, otonomi pengambilan keputusan.

Pemberi-kerja sebaiknya menetapkan kebijakan yang dapat membuat karyawan merasa aman, seperti perjanjian kerja yang jelas dan sesuai Undang-Undang Ketenagakerjaan, dan juga memberikan asuransi atau pensiun. Perusahaan juga perlu memperhatikan bagaimana cara pemberian otonomi pengambilan keputusan melalui gaya kepemimpinan yang bisa menumbuhkan kepercayaan diri dalam mengambil keputusan.

\section{DAFTAR PUSTAKA}

Angeline, T., 2011, 'Managing generational diversity at the workplace:expectations and perceptions of different generations of employees', African Journal of Business Management, 5/2, 249-255
Berthon, P., Ewing, M. L. L. Hah., 2005, 'Captivating company: dimensions of attractiveness in employer branding', International Journal of Advertising, 24(2), 151-172.

Broadbridge, A., et al., 2007, 'Experiences, perceptions, and expectations of retail employment fo Generation Y', Career Development International, 12 (6), 523-544

Broek, M., 2015, 'From Employer Attractiveness to Employer Branding: Results of a Mixed Methods Research' University of Twente.

Jiang, T \& Iles. P., 2011, 'Employerbrand equity, organizational attractiveness and talent management in the Zhejiang private sector', China. Journal of Technology Management in China, 6/1, 97-110.

Kompas.com, 2017, Generasi Y Doyan Pindah-Pindah Kerja?, viewed 2 Mei 2017, from http://nasional.kompas.com/read/201 7/02/11/17141441/generasi.y.doyan. pindahpindah.kerja.simak.kompas.minggu. 1 1.2.2017.

Onibala, T., 2016, 'Komitmen Organisasi Generasi Y di Jakarta', Universitas Bunda Mulia.

Onibala, T \& Novita, 2016, 'Pengaruh Dimensi-Dimensi Pembentuk Merek Perusahaan Pemberi-Kerja terhadap Niat Melamar Pekerjaan dengan Reputasi Perusahaan sebagai Peubah Pemediasi', Journal of Business \& Applied Management, 9 (1), 81- 105.

Pew Research Center, Millenials surpass Gen Xers as the largest generation in U.S labor force, viewed 25 September 2016, from http://www.pewresearch.org/facttank/2015/05/11/millennials-surpass- 
gen-xers-as-the-largest-generationin-u-s-labor-force/

Swa.com, Ini Plus Minus Mempekerjakan Gen $Y$, viewed 2 Mei 2017, from https://swa.co.id/swa/trends/businessresearch/ini-plus-minusmempekerjakan-gen-y
Wallace, M., et al., 2014, 'Attracting and Retaining Staff: The Role of Branding and Industry Image' Workforce Development Perspectives and Issues, XVIII, 387. 